\title{
A PRODUÇÃO DOS SIGNOS NUMA ESTRUTURA SOCIAL ANTAGÔNICA *
}

Lauro Frederico Barbosa da Silveira **

TRANS/FORM/AÇĀO/23

SILVEIRA, L.F.B. da - A produção dos signos numa estrutura social antagônica.

Trans/Form/Ação, São Paulo, $3: 81-90,1980$.

RESUMO: A partir de objeções às proposições de Mikhail BAKHTIN (ou V.N. VOLOCHINOV) sobre a produção da linguagem e do discurso literário no interior das relações sociais de produção, sugere_se a aplicação da semiótica peirceana, devidamente criticada para a análise da produção dos signos no nível da representação da consciência. Pretende-se com isto considerar o signo em toda a sua extensão, e não reduzido ao mero domínio do "“simbólico"”, e tornar mais claro o lugar e o papel das diversas formas ideológicas no interior da "praxis".

UNITERMOS: Semiótica, ideologia, produção social dos signos, juízo percep. tivo Sinsigno dicente.

\section{A PRODUÇÃO DOS SIGNOS NUMA ESTRUTURA SOCIAL ANTAGÔNICA}

Os signos em suas diversas formas de apresentação e de estruturação são formas sociais de representação e de expressão, devendo ser analisadas como integrando um processo de produção e sendo por ele determinadas.

E nos signos que a consciência se forma, não tendo precedência lógica ou histórica sobre eles. E neles que a consciência representa a si e ao universo constituído pela multiplicidade das relações fenomênicas.
No interior da tradição do materialismo dialético deve-se salientar a análise filosófica da linguagem realizada por $\mathbf{M}$. Bakhtin (2), na medida em que, como pioneiro da abordagem do problema, coloca, com rigor dificilmente alcançado posteriormente, a instância da representação em suas relações com as relações de produção e em que estabelece os diversos níveis em que se produz a ideologia, desde a linguagem cotidiana até as diversas formas de ideologias institucionalizadas. Permite que no interior da argumentação seja caracterizado o modo, ou os

* Comunicação pronunciada pelo autor na mesa de debates sobre "Linguagem e Antagonismos Sociais", durante a IV Jornada de Filosofia e Teoria da Ciências Humanas na Faculdade de Educação, Filosofia, Ciências Sociais e da Documentação da UNESP Campus de Marília, no dia 16 de outubro de 1979.

* Professor Assistente Doutor junto ao Departamento de Filosofia da Faculdade de Educação, Filosofia, Ciências Sociais e da Documentação da UNESP - Campus de Marília. 
SILVEIRA, L.F.B. da - A produção dos signos numa estrutura social antagônica. Trans/Form/Ação, São Paulo, 3:81-90, 1980.

modos, como se representam os antagonismos sociais decorrentes da estrutura de produção.

O filósofo russo conduz, porém, seu estudo para ressaltar o surgimento, no interior do discurso literário, da consciência individual do autor, culminando seu trabalho com a análise na Rússia, na Alemanha e na França do discurso indireto livre.

Limita também o âmbito do signo. Considera somente o signo geral (ou símbolo), chegando a excluir da instância ideológica signos de formação menos convencional, colocando-os na classe dos meros sinais exteriores ao domínio da consciência.

A discussão com as correntes da linguagem por ele denominadas de "objetivismo abstrato" e de "subjetivismo idealista", coloca o autor preferentemente dentro do âmbito da linguagem verbal, privilegiando o discurso de ficção.

As condições da produção do signo mergulham-no, porém, no intrincado bem mais complexo das relações sociais que plasmam a consciência e a conduta dos agentes.

A consciência não emerge imediatamente no simbolismo e não é somente aí que se situa. A produção social do signo, a conseqüente formação da consciência e a determinação da conduta implicam as relações efetivas das forças materiais de produção e seus desdobramentos possíveis e, desde aí, o domínio semiótico já se encontra presente e já atua.

Apesar de todo o esforço de conduzir o signo para o âmbito concreto da fala e de encontrar um instrumental teórico adequado para compreendê-lo, por limitar o signo ao domínio do simbólico, assume
Bakhtin a ambígua interpretação da superestrutura como sobreposta à infraestrutura e não como um viés específico de considerar todo o conjunto das relações sociais.

Nenhum nível de apropriação da natureza e da produção deixa de ser representativo e formador da consciência. Não se trata de estabelecer um limiar da gênese da consciência mas de se considerar o aspecto representativo do conjunto total da interação das forças produtivas. Deve-se conseqüentemente, elaborar um instrumental teórico que fundamente a apreensão do signo, de seu estatuto e funções, em todos os momentos de sua realização. Cabe também, a partir deste equacionamento que, concordamos com o autor, deve possuir a generalidade própria da abordagem filosófica, estabelecer procedimentos científicos especiais de apreensão e análise do empírico.

Creio que é necessária uma filosofia da linguagem coerente com a dialética materialista para a compreensão do fenômeno social da produção do signo, mas esta filosofia não pode discriminatoriamente simplificar o domínio do signo, reduzindo-o a uma classe já demasiadamente geral - Isto implica desfigurar o fenômeno semiótico da consciência e as próprias relações sociais de produção.

Por outro lado, que o "discurso" literário seja uma forma privilegiada para manifestar a formação da consciência num determinado momento histórico não julgo haver maiores objeções, desde que a formação social qu z se esteja considerando tenha não somente a fala mas a escrita ocupando um papel dominante na representação das relações sociais, na consciência das mesmas. Mas isto nem sempre se dá, e quando é o caso, deve-se levar em conta "quem" não só fala mas "quem" escreve, "quem" tem seus escri- 
SILVEIRA, L.F.B. da - A produção dos signos numa estrutura social antagônica. Trans/Form/Ação, São Paulo, 3:81-90, 1980.

tos publicados e "quem" tem seus escritos publicados reconhecidos como literários. Ou seja, deve-se determinar de que consciência se está tomando conhecimento ao se analisar o "discurso" - utilizando a terminologia de Bakhtin.

A obra de Bakhtin a que me refiro conduz à formação deste "discurso" literário e aí encontra índices de um aspecto reconhecidamente importante da consciência na sociedade burguesa: o da formação da consciência do autor como indivíduo, capaz de dominar e interpretar a ação e a ideologia da personagem.

Que o modo capitalista de produção tenha permitido a plena formação da consciência individual é, como sabemos, reconhecido por Marx (p. ex. 6, pg. 557 nota 306 e em especial pg. 558-559) como uma aquisição positiva para a humanidade, se bem que ainda vazada pelo antagonismo da divisão entre capital e força de trabalho.

Vale, consequientemente, o trabalho de Bakhtin para revelar no interior do "discurso" literário uma dimensão importante do complexo domínio da formação social da consciência. E que especialmente este fenômeno tenha sido salientado pelo autor, nada há de criticável, pois a ninguém é possível apresentar em minúcias todos os aspectos ideológicos determinados pelas relações sociais de produção.

A questão que levanto, porém, é mais fundamental: o signo em sua efetivação é atravessado pelos antagonismos das relações sociais de produção. A consciência social não só não é única mas é intrinsecamente conflitante. Baḱkhtin não desconhece isto, mas não explicita suficientemente as figuras deste antagonismo nas produções concretas que são por ele analisadas.
Há uma luta real e concreta de domínio sobre os signos e sobre a formação social da consciência. Os signos, assim como os "discursos" decorrentes, são um campo de constante luta para sua apropriação pelas partes em conflito, ao nível de sua forma, de seu registro, da freqüência de sua emissão e recepção, na determinação de sua "significação" e "valoração" - para usar a terminologia do autor. Se no discurso literário, o "autor" assume uma individualidade crescente e um domínio progressivo e consciente sobre a "personagem", como se coloca este autor no interior das relações concretas que determinam a sociedade? Como falam os outros, se é que têm direito a falar e serem ouvidos? Como se estrutura, pois, a sociedade ao nível dos signos, para então saber como o conjunto pode ser elucidado pelos resultados da análise de um determinado aspecto de determinado tipo de discurso literário?

Denunciados os assuntos que me parecem limitativos na dificilmente superada empresa do pensador russo se a consideramos do ponto de vista da fidelidade ao materialismo dialético ao nível da produção da linguagem, sou levado a crer que falta a Bakhtin um instrumental de análise semiótica mais adequado para trabalhar o domínio da produção social do signo em toda a complexidade com que se apresenta. Porque ele não o inventou e nem mesmo manifestou as limitações dos recursos que dispunha e dos consequientes resultados que chegou, deveria ser objeto de estudo por uma crítica da ideologia. Não é este, porém, o objeto desta apresentação. O que pretendo é lançar a hipótese de uma semiótica que parece mais capacitada a abordar o fenômeno com maior respeito a sua integralidade.

Tudo me leva a crer que no momento em que Marxismo e Filosofia da 
SILVEIRA, L.F.B. da - A produção dos signos numa estrutura social antagônica. Trans/Form/Ação, São Paulo, $3: 81-90,1980$.

Linguagem foi escrito e publicado, este instrumental semiótico mais adequado já existia, se bem que a ele Bakhtin muito provavelmente não tenha tido acesso e essas barreiras à circulação de idéias, seriam também um objeto de alta relevância para estudo da produção social dos signos - - O instrumental a que me refiro, se devidamente criticado em suas manifestas deficiências e compromissos de ordem ideológica, apresenta desde o início um duplo credencial para ser, se não assumido, ao menos considerado em sua adequação ao tratamento do fenômeno: ele não cai quer no "idealismo" denunciado por Bakhtin nas propostas encarnadas, por exemplo, pelos vosslerianos e nem mesmo num certo "idealismo" do qual, a meu ver, o próprio filósofo russo não consegue totalmente se livrar. Também não integra a corrente do "objetivismo abstrato" igualmente criticada, a qual é tão bem representada por Ferdinand de Saussure e seus seguidores.

Quero me referir à Semiótica elaborada por Charles Sanders Peirce. Esta teoria, se considerada no conjunto do sistema filosófico em que se insere e no qual assume seu pleno significado, poderia oferecer ao filósofo marxista da linguagem meios para analisar a produção e a função do signo dentro do complexo sociológico e psicológico que explica a formação da consciência e do quadro ideológico atravessado pelos antagonismos da estrutura social, sobretudo ao se tratar da formação econômico-social capitalista.

Volto a reafirmar que a contribuição que poderia trazer a semiótica peirceana não se faz notar de imediato e nem pode ser assumida antes de submetida a uma crítica rigorosa. O que é proposto pelo filósofo não é a análise da produção social do signo; em sua visão do social, não se explicitam os conflitos ideológicos e, menos ainda, são estabelecidas as relações entre a instância da representação da consciência e a estrutura social determinada pelas relações de produção.

Mas o modo como o sistema peirceano apresenta as condições de produção dc signo e suas funções, não só não me parece incompatível com as exigências da dialética materialista para a compreensão crítica da história, e conseqüentemente da formação da consciência em suas múltiplas realizações, como dá lugar para que o processo semiótico se manifeste sistematicamente em todos os seus níveis de representatividade e em suas diversas formas de enunciação.

Certamente a proposta peirceana não cai sob os vícios apontados por Bakhtin no "objetivismo abstrato", (cf. 2, págs. 76 a 95), ou no "subjetivismo idealista" (cf. 2, págs. 98 a 113).

Não cai sob as teses inaceitáveis para Bakhtin do "objetivismo abstrato" sobretudo por não estabelecer a separação entre o ato da fala e a língua como código; não estabelece o corte entre o sincronismo do sistema e a diacronia da evolução histórica dos signos, não elimina do lógico e do racional a concretude da produção dos signos.

O signo é sempre tomado como ato de pensar e como um processo que se desenvolve historicamente mesmo quando submetido à análise lógica. Sua referência primordial é a conduta humana no tempo (cf. 5 CP. V, 120-150). A crítica peirceana ao positivismo e ao empirismo recai sobre a desfiguração que provocam da consciência-pensamento e, conseqüentemente, da não assunção da história na produção semiótica (cf. 5 CP. II, 755).

Não cai também no modo de encarar a linguagem característico do "subjeti- 
SILVEIRA, L.F.B. da - A produção dos signos numa estrutura social antagônica. Trans/Form/Ação, São Paulo, $3: 81-90,1980$.

vismo idealista". De modo algum separa a consciência da manifestação sígnica, afirmando que não há pensamento sem signo e que a própria consciência é formada no interior do processo semiótico. (cf. 5 CP. I, 144; II, 250-253).

$\mathrm{O}$ "não-Eu" precede lógica e fenomenologicamente o "Eu", mesmo no momento mais originário da formação da consciência. (cf. 5 CP. I, 332-334). E não há hiato entre a expressão interior e a instância de representação e da comunicação: todo o pensamento é dialógico (Cf. 5 CP. V, 421).

Se bem que não seja objeto de consideração explícita a precedência do social sobre o individual, nunca porém Peirce propõe a precedência inversa. Ao contrário, o indivíduo ao nível da consciência já é a resultante da interação com um universo de "representamina" (signos em potencial), interação esta que constitui a gênese da consciência. Considerando o meio real em que tal interação se efetua, deve-se concluir que o universo que dá origem à consciência já é trabalhado socialmente e é marcado pelo conjunto das formas ideológicas vigentes no momento histórico. $\mathrm{O}$ indivíduo se diferencia e toma consciência por interagir com um mundo que já se apresenta como mundo da cultura. (cf. 5, CP. I, 321322).

A transcedentalidade kantiana, que confere à percepção e aos juízos a possibilidade de serem dotados de estrita necessidade e universalidade, é recusada por Peirce. Mas o Empirismo, que não reconhece a instância ativa e generalizadora do pensamento, também não é aceito pelo filósofo.

Se não aceita sem restrição a proposta hegeliana - e aí talvez fosse possível suspeitar alguma incompatibilidade com o materialismo histórico - tudo me leva a crer que tal restrição atinge mais a concepção unificada da História através do processo de superação das formas de representação e da convergência ao Espírito Absoluto. O potencial, o concreto (atual) e o geral para Peirce não sofrem uma dinâmica de negação $\mathrm{e}$ superação, mas permanecem em sua especificidade apesar do caráter sintético do pensamento, e tendem mesmo a se reproduzirem indefinidamente, compensando a progressiva ordenação que o pensamento produz scbre o universo fenomênico. Tratar-se-ia de uma espécie de correção pela abertura de constantes alternativas de um processo assintótico rumo a uma entropia de super-ordenação; uma espécie de "feed-back" do novo contra um total domínio da lei. (cf. 5, CP. VI Scientific Metaphysics).

Perguntaria se a proposta do materialismo histórico não suportaria plenamente esta correção à teleologia, superando em seu proveito a tendência à utopia?

Mas é a própria noção de signo para Pierce e seus desdobramentos que, sem dúvida, representam para a análise da produção do signo a inestimável contribuição da Semiótica.

Julgo poder reunir na seguinte formulação, um pouco esquemática, os elementos fundamentais propostos por Peirce à definição de signo, tantas vezes e diversamente enunciadas (cf. 5, CP. II, 230; 274; 3 CP. VIII, 33): o signo é algo que sob algum modo ou aspecto, se relaciona a um outro (seu objeto) para uma mente interpretante. Esta mente podendo e, ousaria dizer, devendo ser social e só por derivação individual.

Uma vez que implica a tríade categnrial fundada na Fenomenologia, que organiza no todo e nas partes o sistema 
SILVEIRA, L.F.B. da - A produção dos signos numa estrutura social antagônica. Trans/Form/Ação, São Paulo, 3:81-90, 1980.

filosófico peirceano, podem-se explicitar relações que permitirão avaliar as possibilidades da semiótica e de sua concepção de signo para o intento que se está considerando.

O signo precisa poder ser signo para, sob algum modo ou aspecto, efetivamente relacionar-se a um outro, mas só é efetivamente signo a partir do momento em que atualmente se refere a um outro. $\mathrm{O}$ signo é signo em ato somente se entrar em conflito com um outro, o qual também podia com ele conflitar-se e constituir-se em seu objeto (5, CP. I, 292; 558ss.).

E o signo só é signo para uma mente interpretante, se puder e efetivamente se referir ao seu objeto - Precisa poder haver uma mente interpretante para que o signo se perfaça. Mas a mente só se atualiza se o signo se referir ao objeto. A gênese da mente como consciência só se efetiva ao interpretar a referência do signo ao objeto. A consciência é nitidamente um terceiro (ou medium) e se configura no universo do signo. Ela é representação existencial, particular ou geral, dos objetos pelos signos e muito em especial, ou melhor, primordialmente, da relação do signo ao objeto para ela .(cf. 5, CP. II, 228).

Convém aqui salientar esta dimensão "para a consciência". Aqui parece-me estar o fulcro da filosofia e, em particular, da semiótica peirceana e é aqui que a meu ver parece situar-se a grande oportunidade de se desenvolver uma filosofia que fundamente a análise da produção social dos signos. Este "para a consciência (interpretante)" significa: para a formação e orientação da conduta atual mas sobretudo futura - o atualmente presente sendo um caso limite deste futuro - , pois o signo só se limita à particularidade do presente por uma certa restrição de sua generalidade, ou para usar a terminologia peirceana, por um processo de degenerência. (cf. 5, CP. II, $265)$.

O signo peirceano está totalmente mergulhado no universo da ação e sua função mais genuina culmina ao programar, pela formação interior do hábito, a conduta futura do sujeito para que, ao se confrontar com um elemento da classe de objetos à qual o signo (ou classe dos signos) se refere, ele atue em conformidade com esta referência.

O signo não é abordado como pertinente a um sistema atemporal, mas como pensamento; e ao se codificar ele o faz enquanto programa em constante formação e desenvolvimento - para a conduta futura. O código ou padrão se for conveniente usar esta terminologia não peirceana - tem lugar próprio na consciência como predisposição a agir de um modo determinado.

E é no agir que o signo se exterioriza assumindo a forma da enunciação, ou as formas a ela correspondentes - se se tratar de signos não verbais ou não matemáticos -, como "réplicas" do pensamento e assim se apresenta para as outras mentes interpretantes (ou para a mente do mesmo sujeito mas enquanto dotada de alteridade). Como receptoras ativas, estas mentes são pressupostas como igualmente produtoras de signos condição "sine qua non" da recepção. (cf. 5. CP. II, 246).

O pragmatismo (ou pragmaticismo) pierceano banha todo o universo de sua filosofia e muito especialmente sua lógica geral ou semiótica. Ele orienta a formação dos conceitos e, por analogia, a formação das outras classes de signos sempre tendo em vista a programação da conduta futura (cf. 5 . CP. V, 18; 402; 438). 
SILVEIRA, L.F.B. da - A produção dos signos numa estrutura social antagônica. Trans/Form/Ação, São Paulo, 3:81-90, 1980.

Se este pragmatismo não reveste a forma dialética da "praxis", a ela não parece refratário. A não consideração das relações sociais da produção e de suas formas de representação por parte do filósofo americano, não infirma seu conceito enquanto determinante da teoria geral dos signos. Pode somente comprometer ideologicamente as consequências para a compreensão pelo autor da conduta social. A prática peirceana não coincide com a "praxis" do materialismo histórico não por uma fundamental incompatibilidade mas por inderterminação.

Se considerarmos que o hábito e a consciência integram no domínio da representação as relações sociais e são, a seu modo, determinados pelas relações de produção, pode-se corrigir tal indeterminação, precisando melhor o papel dos agentes na produção dos signos e do significado destes na moldagem da conduta. Introduzem-se fatores de determinação mais caracterizados sem em nada infirmar uma teoria dos signos que se apresenta como um sistema extremamente bem elaborado e constituido de conceitos claros e altamente operacionalizáveis da qual, é esta minha impressão, ao menos no que diz respeito a conceitualização de signo, tenta aproximar-se Bakhtin de um modo um pouco tateante.

A "prática" do signo em Peirce vai construindo historicamente cadeias infinitas de interpretantes que explicitam não necessariamente num processo linear - as relações do signo com o objeto para os agentes, nos quais vão se formando os hábitos de conduta futura. (cf. 5. CP. II, 274).

Como não se trata de cadeias abstratas, pesam aí as valorizações que a comunidade imprime a essas relações e sobretudo à direção desta conduta. Deste modo vão se definindo o "real" e o "verdadeiro" para a comunidade dos agentes. (cf. 5. CP. V, 403; 457). Assim vai se formando a consciência.

Esta prática é a instância de representação das relações sociais e estas comportam os antagonismos determinados pela luta pela apropriação da produção. A imposição de um hábito de conduta que se faz pela determinação das cadeias de interpretantes é o modo como, ao nível do signo, da consciência e da ideologia, situam-se os antagonismos estruturalmente existentes entre os agentes da produção. O que pretende a ideologia senão determinar, induzir uma certa forma de conduta social e uma certa direção que esta deve tomar pela imposição de um programa que, interiorizado pelos agentes (em estrutural antagonismo), seja por eles aceito como o único verdadeiro e o único real?

A classe dominante impõe, pelo efetivo domínio sobre os meios de produção, não só os signos que lhe convém mas a classe de objetos a que se referem-se apossando de condições muito propícias e eficazes de impregnar as mentes interpretantes com cadeias de interpretantes tais que conduzam, em favor de seus interesses, a conduta social não só dela mesma mas também da classe dominada.

A eficiência desta estratégia é sobejamente demonstrada na história seja qual for a formação economico-social prevalecente e atinge, inclusive, aquelas determinadas pelo tradicionalmente denominado "modo de produção primitivo" que estruturalmente não conhece a divisão entre trabalhadores diretos e não trabalhadores, como bem apresenta Marc Augé a respeito de duas sociedades africanas (cf. 1. pgs. 55 a 67). Lembraria também, sobretudo por analisar como o instrumental semiótico peirceano um caso 
SILVEIRA, L.F.B. da - A produção dos signos numa estrutura social antagônica. Trans/Form/Ação, São Paulo, 3:81-90, 1980.

concreto desta imposição de um interpretante intersemiótico profundamente rígido e socialmente discriminatório — pois só serve para os interesses da classe dominante - o artigo de Lucrécia D'Alessio Ferrara, Poluição visual e leitura do ambiente urbano (4, págs. 63 a 79).

Mas a formação dessas cadeias de interpretantes não amolda tranquilamente a consciência da classe dominada nem obtem um controle total e irreversível de sua conduta. Sem acesso ao controle dos canais sociais de comunicação, esta classe fica em nítida desvantagem para impor seu "discurso", determinar a classe de objetos a que se refere e influenciar na construção das cadeias de interpretantes que constituirão os programas de conduta social. E neste momento que a semiótica peirceana revela, a meu ver, mais um aspecto de sua capacidade de analisar a produção social do signo. Considerando não somente o signo em sua realização mais genuina, ou seja, o signo constituido por uma lei ou nítida convenção (legisigno) referente a uma classe geral de objetos (símbolo) e propondo-se à mente interpretante pela coerência e o grau de convencimento próprio de uma lei do pensamento (Argumento), contempla formas menos generalizadas de signo e as trata sistematicamente. (cf. 5. CP. II, 250-253).

Quero ressaltar aqui a classe de signos que mais claramente revela à classe dominada a falsidade da ideologia dominante e' estabelece as condições mais concretas da formação da consciência e, consequentemente, de resistência à submissão aos signos que lhe são impostos, abrindo um espaço para a formação de um discurso gerado de cadeias de interpretantes de natureza crítica e revolucionária. Trata-se de um conjunto de signos cuja forma genuina na classificação peirceana é representada pelos sinsignos di- centes (cf. 5. CP. II, 257). Na classe de fenômenos a que me refiro, trata-se dos signos constituidos pela própria realidade física em seu embate concreto com o corpo do trabalhador e da produção concreta da consciência de sua existência, ao nível que Peirce denomina de Juizo Perceptivo (cf. 5 CP. II, 773). O desgaste gerado do ritmo do trabalho e da locomoção diária na grande cidade; da fome; do frio ou do calor excessivos; do impacto dos diversos agentes poluidores e da doença, contrasta com o próprio vigor e valor real da força física e mental despendida, sobretudo quando experimentada coletivamente.

Sem dúvida, tomado neste nível, o signo é gerado em sua máxima concretude e imediatez e é insuficientemente para mover a classe dominada a uma coerente e coesa conduta política de combate à expropriação de que é vítima. Constitui-se, no entanto, em pré-condição de um processo mais semiotisado de consciência. Pode também manter-se em sua particularidade, gerando formas de representação e de conduta ideologicamente inadequadas para a real superação desta dominação.

Desta experiência concreta, constituída de muitos elementos pré-simbólicos mas, em termos peirceanos, de natureza estritamente semiótica, pode ir se efetivando a apropriação concreta de signos mais gerais - e isto a partir da percepção de novas formas possíveis de elaboração de signos, de relação a objetos condutores de novas direções da conduta (bem revelada na multiplicidade de metáforas e de figuras produzidas ao nível da classe dominada - piadas, poesias, grafiti, etc.). Podem ir se constituindo formas de representação que representem mais claramente a defazagem entre o valor de uso efetivo da força de trabalho e de seu valor de troca no mercado de trabalho; o valor do produto do trabalho e o trabalho nele coagulado e o preço pago por esta 
SILVEIRA, L.F.B. da - A produção dos signos numa estrutura social antagônica. Trans/Form/Ação, São Paulo, 3:81-90, 1980.

força de trabalho: - o peso da mais valia absoluta e relativa que pesa sobre o trabalhador. Critica-se o "significado" (compreendido no interior da tríplice relação constitutiva do signo) falso e venal do programa induzido pela classe dominante em sua política de propaganda e de doutrinação quando comparado com o efetivo valor da força de trabalho dispendida pela classe dominada e com as necessidades concretas para a sua reprodução (programas suntuosos $\mathrm{X}$ custo de vida, por exemplo). Aperfeiçoa-se um discurso próprio (pluris semiótico) que começará a coordenar a conduta, antes totalmente dispersa e fragmentada, $\mathrm{da}$ classe dominada. Dispersão e fragmentação gerada pelas leis técnicas do modo de produção e incentivada pelos diversos recursos de que dispõe a classe dominante para impor sua ideologia. Evidentemente, a correlação de forças no interior do domínio dos signos sendo estruturalmente conflitante e extremamente complexa, todo c processo de seu desvendamento pela análise teórica será sempre provisório e duplamente parcial.

Provisório, por se realizar no interior da dinâmica das relações sociais e parcial, não só porque nunca será capaz de abranger todos os níveis e todos os setores em que o antagonismo se realiza, como se fará no interior do próprio conflito, marcado ideologicamente por quem a efetiva.

Mesmo que assumido no interior de uma "praxis" política, este processo sem. pre estará sujeito a equívocos metodológicos e mesmo de ordem ideológica de interpretação e de valorização dos dados analisados.

O que me parece, no entanto, justificável pode resumir-se nos seguintes tópicos, os quais não pretendem, porém, ser completos ou dotados da melhor formulação:

$\left.1 .^{\circ}\right)$ Assumir a produção dos signos no interior das relações sociais da produção, e como condição e "lugar" da formação da consciência.

$\left.2 .^{\circ}\right)$ Tomar o domínio do signo em toda sua amplitude, pois só assim será possível considerar a integridade e a integralidade da formação da consciência.

$\left.3 .^{\circ}\right)$ Considerar a instância da representação da consciência como coextensiva das relações sociais de produção, se bem que possa apresentar formas e níveis de realizações diversas - atingindo até $o$ nível estável das instituições - e que seja sempre estruturalmente determinada pelas relações de produção.

$\left.4 .^{\circ}\right)$ Reconhecer que ao nível da produção dos signos reproduzem-se de modo específico os antagonismos sociais decorrentes da estrutura da produção de uma dada formação economico-social.

$\left.5 .^{\circ}\right)$ Exigir um instrumental analítico adequado à produção semiótica ("energeia") na integralidade de seus níveis e em todas as suas formas de representação, expressão e enunciação, assumindo seu caráter social e a "praxis" em que se insere.

$\left.6^{\circ}\right)$ Deduzir das hipóteses teóricas da teoria semiótica, as condições verificáveis empiricamente e, efetivamente, verificá-las.

A adoção da teoria peirceana como modo de análise, como é possível constatar, encontra-se ainda, ao menos da parte de meus estudos, num estágio de reelaboração para que dê conta, em nível meramente conjectural, do fenômeno da produção social do signo. Mesmo sua compatibilidade com uma análise dedu- 
SILVEIRA, L.F.B. da - A produção dos signos numa estrutura social antagônica. Trans/Form/Ação, São Paulo, 3:81-90, 1980.

zida do materialismo histórico não ultrapassa as fronteiras da sugestão. Sua natureza filosófica a coloca num nível de generalidade tal que exige particularizações mais precisas para a abordagem se- gura dos fenômenos empíricos. Coloco-a em discussão na espera que seja devidamente criticada de modo que possa, quanto antes, ser corrigido o encarninhamento de meu trabalho.

\section{TRANS/FORM/AÇÃO/23}

SILVEIRA, L.F.B. da - The production of signs in a antagonistic social structure. Trans/Form/Ação, São Paulo, $3: 81-90,1980$.

SUMMARY: Contrary to some propositions of Mikhail Bakhtin (or N. V. Volochinov) concerning the production of language and of literary discourse, it is proposed a critical application of the peircean Semiotics to the analysis of the production of signs on the level of the representation of conscience. The purpose in doing so is to consider the sign in its whole breadth, not reduced to the mere domain of the "symbolic", and to make clearer the place and role of the several ideological forms within the "praxis".

UNITERMS: Semiotics; ideology; social production of signs; perceptive judgement; dicent_sinsign.

\section{REFERENCIAS BIBLIOGRÁFICAS}

1. AUGÉ, Marc Quand les signes s'inversent. $\bar{A}$ propos de quelques rites africains. Communications, Paris, 28:55-67, 1978.

2. BAKHTIN, Mikhail (V.N. VOLOCHINOV) - Marxismo e filosofia da linguagem, problemas fundamentais do método sociológico na ciência da linguagem, 1929-1930. Trad. de Michel Lahud e Yara Frateschi Vieira. São Paulo, Hucitec, 1979.

3. BURKS, Arthur W., ed. Collected papers of Charles Sanders Peirce. Cambridge, Harvard University, 1958 , v. 7,8.
4. D'ALESSIO FERRARA. Lucrécia. Poluição visual e leitura do ambiente urbano. Através, São Paulo, 1:63-79, out. 1975.

5. HARTSHORNE, Charles \& WEISS, Paul, ed. Collected papers of Charles Sanders Peirce. 3rd priting. Cambridge, Belknap / Harvard University Press, 1974, v. 1-6.

6. MARX, Karl. O capital. Trad. de Reginaldo Sant'Ana, Rio de Janeiro, Civ. Brasileira, 1968, L. 10, V.1, cap 13. 